\title{
Editorial:
}

\section{El Covid-19 y las Brechas Educativas}

\section{The Covid-19 and the Educational Gaps}

\author{
F. Javier Murillo ${ }^{*}$ \\ Cynthia Duk ${ }^{2}$ \\ ${ }^{1}$ Universidad Autónoma de Madrid, España \\ ${ }^{2}$ Universidad Central de Chile, Chile
}

Resulta prácticamente imposible en estos momentos difíciles abstraerse de la situación que monopoliza todos nuestros pensamientos y acciones cotidianas y no dedicar esta breve reflexión al Coronavirus y sus efectos en la educación de los más vulnerables. A un lado y al otro del charco, vivimos en estado de emergencia, lo que significa confinamiento en las casas y, con ello, suspensión de toda actividad educativa presencial.

Y también resulta bien difícil escribir algo que tenga una mínima permanencia en el tiempo. Si algo hemos aprendido en este periodo es la provisionalidad de todo: lo que ayer valía hoy no sirve y quién sabe si mañana. Por eso, seguramente muchas de estas letras resaltadas en negro sobre blanco quedarán añejas en el momento en que la revista vea la luz ante la devastadora propagación de la pandemia a nivel global. Pero este sentimiento de provisionalidad no nos impide que nos sentemos a escribir.

Salvo muy contadas excepciones, hoy por hoy la totalidad de países en todo el mundo ha decretado el cierre de los centros educativos en todo el país, y los que no lo han hecho, como el caso de Suecia, lo están pagando en extensión de la pandemia. Esta medida, como ya señaló acertadamente la UNESCO, tendrá unas consecuencias muy negativas tanto sociales como económicas. Así, apuntaba a cuestiones tales como: interrupción del aprendizaje; insuficiente alimentación; falta de preparación de los padres para la enseñanza a distancia o desde la casa; acceso desigual a las plataformas de aprendizaje digital; insuficiencias en materia de cuidado de los niños; costos económicos elevados; incidencia mecánica en el sistema de salud; aumento de la presión para los centros escolares que permanecen abiertos y tendencia al incremento de las tasas de abandono escolar.

Todos esos elementos, y así lo reconoce la propia UNESCO, no afectan por igual a todos los niños, niñas y adolescentes. En algunas cuestiones solo afecta a algunos y en otras de manera desigual. ¿Y quienes acaban perdiendo? Pues los (y las) de siempre.

En estos tiempos, vale resaltar el rol social insustituible que juega la institución escolar en el reconocimiento y compensación de las diferencias de origen. A pesar de todos los problemas, y aun sabiendo que es el mecanismo más eficaz de legitimación de las desigualdades sociales, es también la herramienta más poderosa para reducir las desigualdades. Por muy malo que sea un sistema educativo, es definitivamente mejor que

*Contacto: javier.murillo@uam.es

ISSN: 0718-7378

www.rinace.net/rlei/ 
si no lo hubiera. Con el cierre de las escuelas, el sistema educativo se queda en su mínima expresión. Y para algunos, prácticamente desaparece.

Uno de los colectivos que más están sufriendo con la crisis del Covid-19 y la consecuente clausura de centros educativos es el de los niños, niñas y adolescentes en situación de discapacidad. Pese a las críticas y a las evidencias que dan cuenta de la menor calidad educativa que suelen recibir estos estudiantes, hemos de reconocer que las políticas y procesos de inclusión impulsados en las últimas décadas, con diferencias entre países, entre regiones y entre escuelas, están dando sus frutos, no solo en términos de acceso y participación, sino también a nivel del aprendizaje. Basta echar la vista atrás unos años para ver que las oportunidades educativas han aumentado para estos estudiantes y la mejora ha sido significativa.

En el contexto de la emergencia sanitaria, los niños, niñas y adolescentes con alguna discapacidad se han visto confinados a sus casas, siendo en general olvidados de las medidas paliativas que los sistemas educativos han tomado para suavizar esta situación. La alternativa de la educación a distancia se convierte para muchos en un imposible. En algunos casos porque no tienen las destrezas o no están preparados en el uso de los dispositivos digitales, o porque los programas y actividades que los sistemas ofrecen a la mayoría no son accesibles para ellos. Pero, aunque si lo fueran, los y las docentes se encuentran absolutamente saturados como para ofrecer la atención más personalizada que muchos de ellos requieren. Además, en muchas partes, se ha suspendido de manera abrupta el apoyo profesional especializado que se les proporcionaba. La combinación de estos factores hace que cientos de estudiantes con alguna discapacidad hayan quedado excluidos de la educación.

Otro colectivo que ha salido especialmente perjudicado es el de los y las estudiantes de familias con menor nivel socioeconómico y dentro de ellos también los migrantes. Este "frenazo en el aprendizaje" del que nos hablaba la UNESCO no tiene las mismas consecuencias para todos los niños, niñas y adolescentes. Para los estudiantes de familias con más recursos, la educación se sigue produciendo, dado que viven en hogares cuyo capital sociocultural y mayores oportunidades tiende a mitigar el impacto en el aprendizaje y los efectos psicosociales que la interrupción de la educación presencial trae consigo; en cambio para los colectivos más desfavorecidos, con frecuencia la escuela es su única salida, la única vía de ejercer su derecho a la educación. La escuela no sólo provee de "alimento espiritual" a los estudiantes, muchos de ellos además necesitan la escuela para poder tener una alimentación suficiente y de adecuada calidad. De nuevo son los que menos recursos tienen los que más sufrirán las consecuencias.

La educación a distancia es una quimera, una alternativa para los que tienen equipos de una cierta calidad con acceso a internet en casa. Pero desgraciadamente hay demasiados estudiantes que no cuentan con ese recurso, ni con las condiciones materiales, ambientales y de espacio para poder beneficiarse de esta opción. No olvidemos que aún hay millones de personas en América Latina, pero también en España o Portugal, que no disponen de luz eléctrica en sus casas. Mas específicamente, solo 4 de cada 10 hogares de Latinoamérica cuenta con conexión a internet. Así, por ejemplo, siendo Chile uno de los países con mayores niveles de conectividad, solo alrededor del $57 \%$ de los hogares cuentan con conexión a red fija. ¿De qué educación a distancia estamos hablando?

Por otra parte, la irrupción de la educación a distancia producto de la emergencia, ha dejado al descubierto la brecha digital existente entre las escuelas y sus docentes. 
Profesores que manejan las tecnologías con sentido pedagógico, que saben cómo diseñar procesos de aprendizaje en entornos virtuales, desafortunadamente son la minoría. La realidad de las escuelas en América Latina es que en su mayoría no cuentan con las competencias necesarias para asumir este tremendo desafío. Sin embargo, en varios casos tanto los sistemas educativos como sus escuelas se han visto enfrentados a la cruda realidad de tener que convertirse, de la noche a la mañana, en centros escolares de "educación a distancia". Algo impensado hace solo algunos meses atrás.

El impacto que el cierre de escuelas y otras restricciones sociales ha ocasionado en los grupos más desventajados, está suscitando gran interés y preocupación a nivel global. Es así, que académicos e investigadores alrededor del mundo han comenzado a desarrollar estudios, recopilando información valiosa y experiencias que aporten con debida rapidez a la generación de políticas nacionales y medidas de apoyo orientadas contrarrestar tales limitaciones. Es fundamental, a su vez, avanzar en el diseño de medidas de más largo plazo que ayuden a enfrentar la vuelta a clases una vez que pase la emergencia, en tanto los efectos de la educación a distancia se trasladarán a la experiencia educativa en las escuelas.

Junto a ello, en toda la región los efectos del confinamiento están haciendo que se llegue a una verdadera situación de emergencia social. Millones de personas se han quedado sin los mínimos ingresos para subsistir, el hambre está incrementándose como no se veía hace décadas. Resulta difícil aventurar o afirmar si las administraciones no quieren, no pueden o no son conscientes de la situación, pero lo que está claro es que en muchos lugares es la sociedad, la comunidad organizada la que está prestando el apoyo necesario. Frente a los desastres de la pandemia emerge con toda su fuerza la esperanza de la solidaridad y de lo público como bien común a cuidar y valorar.

Esta situación afecta de manera especial a los niños y niñas. Así, ¿de qué educación estamos hablando si no hay para comer?

No sabemos cómo será el futuro. Si la economía, las relaciones, la educación ... la vida... cambiarán cuando todo esto pase. No sabemos si empezaremos a valorar lo que de verdad es importante y entonces construyamos un sistema educativo que de verdad acabe con las desigualdades y las injusticias ocupándose de los que más necesitan. Una educación que "nos cuide". Quizá todo siga igual, quizá nada siga. Ahora solo cabe seguir luchando sin perder la esperanza de un mundo mejor para todos. 